\title{
Research article \\ Differential binding of chemokines to macrophages and neutrophils in the human inflamed synovium
}

\author{
Angela M Patterson, Caroline Schmutz, Scott Davis, Lucy Gardner, Brian A Ashton and Jim Middleton
}

Leopold Muller Arthritis Research Centre, Centre for Science and Technology in Medicine, Keele University at Robert Jones and Agnes Hunt Orthopaedic Hospital, Oswestry, Shropshire, UK.

Correspondence: Dr Jim Middleton, LMARC, Robert Jones and Agnes Hunt Orthopaedic Hospital, Oswestry, Shropshire SY10 7AG, UK. Tel: +44 (0)1691 404149; fax: +44 (0)1691 404170; e-mail: Middleton1@hotmail.com

Received: 30 March 2001

Revisions requested: 25 May 2001

Revisions received: 31 October 2001

Accepted: 12 December 2001

Published: 31 January 2002
Arthritis Res 2002, 4:209-214

(C) 2002 Patterson et al., licensee BioMed Central Ltd (Print ISSN 1465-9905; Online ISSN 1465-9913)

\begin{abstract}
In chronic inflammatory foci, such as the rheumatoid joint, there is enhanced recruitment of phagocytes from the blood into the tissues. Chemokines are strongly implicated in directing the migration of these cells, although little is known regarding the chemokine receptors that could mediate their chemotaxis into the joint tissue. Therefore the objective of the study was to identify chemokine binding sites on macrophages and neutrophils within the rheumatoid synovium using radiolabeled ligand binding and in situ autoradiography. Specific binding sites for CCL3 (macrophage inflammatory protein-1 $\alpha$ ), CCL5 (RANTES), CCL2 (monocyte chemoattractant protein-1) and CXCL8 (IL-8) were demonstrated on $\mathrm{CD} 8^{+}$macrophages in the subintimal and intimal layers. The number and percentage of intimal cells that bound chemokines were greater in inflamed regions compared to noninflamed regions. The intensity of intimal binding varied between chemokines with the rank order, CCL3 > CCL5 > CCL2 > CXCL8. Neutrophils throughout the synovium bound CXCL8 but did not show any signal for binding CCL2, CCL3 or CCL5.

Immunohistochemistry showed that both CXCR1 and CXCR2 are expressed by macrophages and neutrophils in the rheumatoid and nonrheumatoid synovia, suggesting that both of these receptors are responsible for the CXCL8 binding. The chemokine binding sites described on phagocytes may be involved in the migration of these cells into the inflamed joint.
\end{abstract}

Keywords: chemokines, inflamed, receptors, synovium

\section{Introduction}

Rheumatoid arthritis (RA) is a chronic inflammatory disease of the synovial joints, which can result in articular cartilage and bone destruction, leading to significant disability. Central pathophysiological features of the disease occur in the synovium, with thickening of the lining layer (or intima) and infiltration of the sublining layer, mainly by macrophages and lymphocytes [1]. In addition, the fluid- filled joint cavity contains numerous neutrophils, particularly during acute flares of RA [2].

The normal intima of the synovium is one to two cells thick and consists mainly of macrophage-like and fibroblast-like cells [3]. In inflammation, macrophages make a large contribution to intimal thickening, where these cells increase in number and proportion [3]. Evidence indicates that

$\mathrm{CC}=$ chemokine with two adjacent cysteine $(\mathrm{C})$ residues near the $\mathrm{NH}_{2}$-terminus; $\mathrm{CCR}=\mathrm{CC}$ chemokine receptor; $\mathrm{CXC}=$ chemokine with $\mathrm{C}$ separated by an amino acid defined as X; $C X C R=C X C$ chemokine receptor; $I L=$ interleukin; PBS = phosphate-buffered saline; $R A=$ rheumatoid arthritis; RANTES = regulated on activation normal T cell expressed and secreted; $r \mathrm{r}=$ recombinant human. 
intimal macrophages arrive via the circulation as monocytes [4], and it is proposed that increased numbers of intimal macrophages in RA are largely attributed to enhanced monocyte recruitment from blood vessels in the synovium $[1,5]$. Neutrophils are also recruited in RA and can be found in abundance in synovial fluid, yet they occur in relatively low numbers in the synovium [5]. In synovial fluid their number can reach $10^{6}$ per joint, particularly during an active phase of the disease [6]. Neutrophils occur at the pannus-cartilage junction [7] and it is presumed that these cells reach the joint cavity by migrating from the blood vessels in the synovium, following a chemotactic gradient.

Chemokines are a family of proinflammatory cytokines, which are strongly implicated in inducing migration of leukocytes from the blood into inflammatory lesions. Evidence has accumulated to suggest that chemokines, such as CXCL8 (IL-8), CXCL5 (epithelial cell-derived neutrophil-activating protein), CCL2 (monocyte chemoattractant protein-1), CCL3 (macrophage inflammatory protein- $1 \alpha$ ) and CCL5 (RANTES), direct the migration of leukocytes into the RA synovium and joint fluid [8]. Chemokines occur in significantly elevated levels in human RA synovial fluid, where they are biologically active, and are expressed by cells of the synovium and cartilage. Tumour necrosis factor- $\alpha$ blockade reduces synovial expression of CCL2 and CXCL8 and reduces inflammatory cell migration into RA joints [9]. In addition, these chemokines, produced by RA synovial stromal cells, have been shown to stimulate monocyte migration [10]. The functional importance of chemokines in joint inflammation has also been established in animal models of RA where antibodies to these mediators significantly reduce both the number of leukocytes recruited and the severity of disease. In addition, administration of chemokines to the joints of animal models results in inflammation and leukocyte recruitment.

The biological effects of chemokines are mediated by binding to G-protein-coupled, seven transmembrane domain, chemokine receptors [11]. CC receptors (CCR) bind members of the class of chemokines with two adjacent cysteine (C) residues near the $\mathrm{NH}_{2}$-terminus (CC; e.g. CCL2, CCL3 and CCL5) and CXC receptors (CXCR) bind members of the class of chemokines with $\mathrm{C}$ separated by an amino acid defined as X (CXC; e.g. CXCL5 and CXCL8). There have been some reports on the expression of such receptors on T cells in synovial tissue and fluid [12-16]. Little is known about the expression of chemokine receptors on phagocytes in the human RA synovium. One recent study has shown the protein expression of several chemokine receptors on monocytes/ macrophages in RA blood, synovium and synovial fluid [17]. The aim of the present study, therefore, was to examine the expression of in situ chemokine binding sites on macrophages and neutrophils that could mediate the migration of these cells into the inflamed synovium.

\section{Materials and methods \\ Tissue source}

Tissue samples were obtained from patients with RA $(n=6)$ who fulfilled the American Rheumatism Association criteria for RA (Supplementary Table 1). Synovia were taken from these subjects at total knee replacement (patients 1, 3-5) or knee synovectomy operations (patients 2 and 6$)$. Non-RA patients $(n=6)$ had knee joint symptoms for suspected articular cartilage, meniscal or anterior cruciate ligament damage (patients 7-12). Knee joint synovial biopsies were obtained from these non-RA individuals, with informed consent, at arthroscopy. For RA and non-RA patients, samples were taken from the suprapatellar pouch and medial gutter, which is reported to provide representative sampling of synovial membrane pathology [18].

\section{In situ binding autoradiography}

The method of Hub and Rot [19] was followed, with minor modifications (see Supplementary Material).

\section{Identification of macrophages and neutrophils}

Representative sections of synovia that had been incubated with $125 \mathrm{l}$-labeled chemokines were immunostained for CD68 as a marker for macrophages. Slides were deparafinized, rehydrated and treated with $1 \%$ pronase for seven minutes at room temperature. Following blocking of endogenous peroxidase, sections were treated with normal horse serum and incubated with $2.5 \mu \mathrm{g} / \mathrm{ml}$ antiCD68 monoclonal antibody (PG-M1, Dako A/S, Glostrup, Denmark) in PBS/normal horse serum. The bound antibody was detected using biotinylated second antibody, avidin-peroxidase conjugate and diaminobenzidine substrate (Vectastain ABC Elite Kit; Vector Labs, Burlingame, USA). Slides were then coated with emulsion, exposed, developed and stained in haematoxylin, as for in situ binding autoradiography.

Neutrophils were identified by their characteristic multilobed nuclei in haematoxylin and eosin stained sections.

\section{Immunohistochemistry of CXCR1 and CXCR2}

Synovial samples that had been examined for chemokine binding were also sectioned and incubated with rabbit polyclonal antibodies to the carboxy termini of CXCR1 and CXCR2 (both from Santa Cruz Biotechnology, Santa Cruz, USA) [20]. Antibody binding was detected using an immunoperoxidase method (Vectastain ABC Elite Kit; Vector Labs, Burlingame, USA). See Supplementary Material for more detailed methods.

\section{Quantitation of synovial sections}

See Supplementary Material. 


\section{Results}

\section{Tissue sampling}

In all six RA subjects the histological appearance of synovia showed classic inflammatory pathology with mononuclear cell infiltrates and a thickened intimal layer. In two of these individuals a minority of synovial samples also showed microscopically normal regions with minimal infiltration of inflammatory cells and an intimal layer of normal thickness (one to two cells thick). The synovia of the six non-RA patients showed inflamed and noninflamed regions. These inflamed regions displayed intimal layer thickening and some infiltration of mononuclear cells, although not as severe as in RA samples, and noninflamed sites showed a normal intimal layer and no leukocyte infiltrates.

\section{Chemokine binding to macrophages}

To examine in situ binding of chemokines, synovia were treated with ${ }^{125} \mathrm{I}-\mathrm{CXCL} 8,{ }^{125} \mathrm{I}-\mathrm{CCL} 2,{ }^{125} \mathrm{I}-\mathrm{CCL} 3$ and ${ }^{125} \mathrm{I}-$ CCL5 followed by autoradiogaphy. For direct comparison, each chemokine was added at the same specific radioactivity and concentration, and autoradiography was performed for an identical exposure time. All four chemokines bound to synovial tissue cells in the subintima and the intima in every RA and non-RA individual (Supplementary Fig. 1a for CCL5). Radiolabelled chemokine binding was absent in synovia treated with 1000-fold excess homologous nonradiolabelled chemokine, indicating that the binding sites were specific (Supplementary Fig. 1b). Histological examination indicated that macrophages accounted for a high proportion of the chemokine binding, so to confirm this observation, representative sections were immunostained with CD68 as a marker of monocytes/ macrophages, then processed for autoradiogaphy. All four chemokines bound to $\mathrm{CD}^{+} 8^{+}$cells in the subintima in every RA and non-RA synovial sample. No major differences in chemokine binding were apparent between the six RA patients, despite variation in disease duration and drug treatment (Supplementary Table 1). The positive cells were located close to blood vessels in leukocyte infiltrates and non infiltrated sites, and in more remote sites within the subintimal stroma (Fig. 1). In addition $\mathrm{CD}^{+} 8^{+}$macrophages bound all four chemokines in the intimal layer of inflamed (Fig. 1) and noninflamed samples. In control experiments there was no immunostaining when isotype-matched control mouse IgG was used instead of the anti-CD68 antibody.

\section{Quantitation of intimal binding}

The number of intimal cells that bound chemokines were counted and the results for RA and non-RA patients were expressed as means (Table 1). There was a significant increase of chemokine-positive cells in inflamed intima compared to noninflamed intima, for both RA and non-RA synovia. The number of positive cells varied between
Figure 1
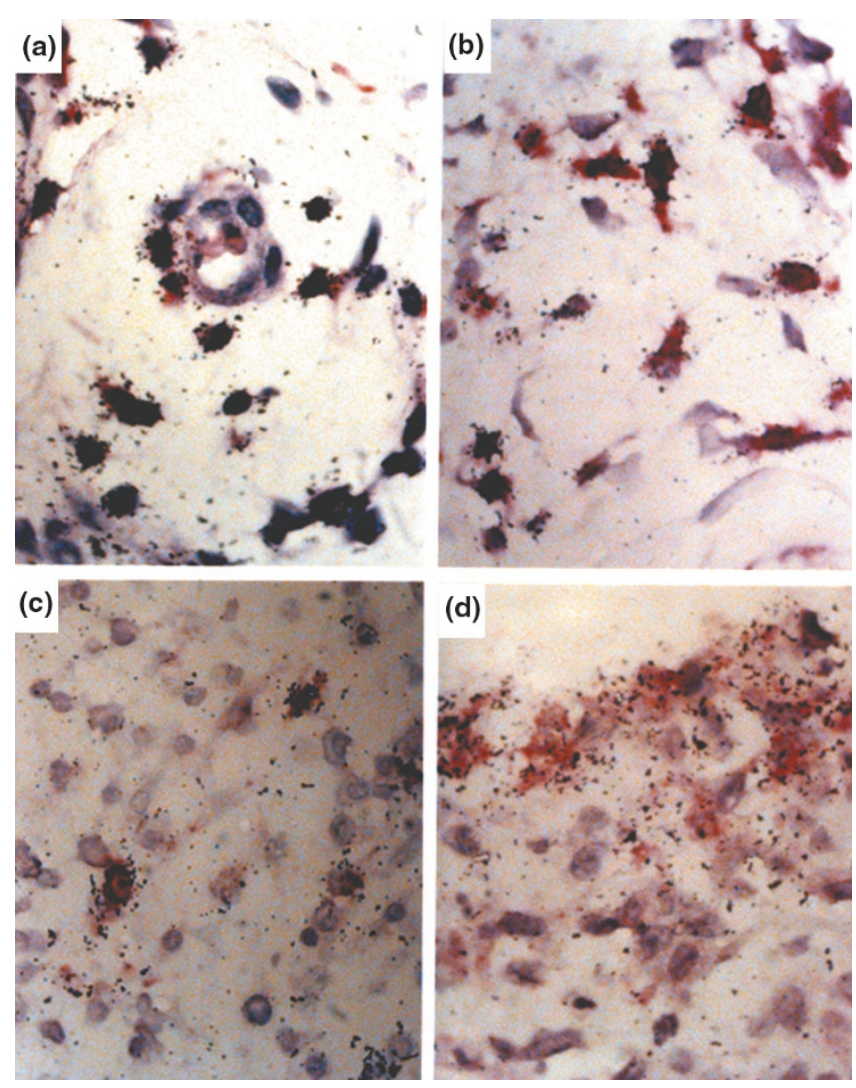

Chemokine binding to $\mathrm{CD}^{+} 8^{+}$monocyte/macrophages (red) in the synovium. (a) CCL5 binding to CD68+ cells around a venule in the subintima of inflamed, nonrheumatoid synovium. (b) CXCL8 (IL-8) binding to macrophages in a macrophage-rich infiltrate in rheumatoid tissue. (c) CXCL8 binding to macrophages in a lymphocyte-rich infiltrate in rheumatoid synovium. (d) CCL3 (macrophage inflammatory protein-1 $\alpha$ ) binding to macrophages in the inflamed intimal layer of rheumatoid synovium. Magnification $\times 470(a)-(d)$.

chemokines and in RA tissue the rank order was, CCL3 $>$ CCL5 > CCL2 > CXCL8. In non-RA tissue the order was, CCL3 > CCL5 > CXCL8 > CCL2. The number of CCL3 and CCL5 positive intimal cells did not differ between RA and non-RA tissue. However, the number of intimal cells binding CCL2 in RA was greater than nonRA synovium. In addition, there were more cells binding CXCL8 in inflamed, non-RA intima compared to inflamed RA tissue.

Data were also expressed as the percentage of intimal cells binding chemokines (Supplementary Table 2). Similar results to data expressed as the number of cells binding chemokines were obtained (Table 1 and Supplementary Table 2). In both RA and non-RA synovia there was a significantly higher percentage of positive cells in inflamed compared to noninflamed intima. The rank order of 
Table 1

The number of cells binding chemokines per $500 \mu \mathrm{m}$ of intima

\begin{tabular}{|c|c|c|c|c|}
\hline \multirow[b]{2}{*}{ Chemokine } & \multicolumn{2}{|c|}{ Rheumatoid $(n=6)$} & \multicolumn{2}{|c|}{ Nonrheumatoid $(n=6)$} \\
\hline & Inflamed & Noninflamed & Inflamed & Noninflamed \\
\hline CXCL8 & $13 \pm 1^{\text {*十 }}$ & $3 \pm 1$ & $22 \pm 2^{*}$ & $5 \pm 1$ \\
\hline CCL2 & $23 \pm 3^{\star \dagger}$ & $10 \pm 1^{\dagger}$ & $15 \pm 3^{*}$ & $5 \pm 1$ \\
\hline CCL5 & $29 \pm 2^{*}$ & $14 \pm 3$ & $25 \pm 3^{*}$ & $10 \pm 2$ \\
\hline CCL3 & $33 \pm 2$ & - & $36 \pm 3^{*}$ & $13 \pm 2$ \\
\hline
\end{tabular}

The number of positive cells per standard length of intimal surface was counted (3360 $\mu \mathrm{m}$ total length per patient); data are expressed separately for inflamed (>2 cells thick) and noninflamed tissue (1-2 cells thick). Data are expressed as mean \pm SE. $n$, number of patients; *significant difference between inflamed and noninflamed; 'significant difference between rheumatoid and nonrheumatoid.

chemokine binding was almost identical whether the data were expressed as percentage or number of cells binding chemokines. In the cases of CCL2, CCL3 and CCL5 there were no differences in the percentages of positive cells between RA and non-RA tissue. A higher percentage of cells, however, bound CXCL8 in non-RA inflamed intima compared to RA inflamed intima.

\section{Chemokine binding to neutrophils}

Neutrophils were present in the synovia of four out of the six RA patients, but they were less abundant than mononuclear cells. Neutrophils were absent in nonrheumatoid synovia. Neutrophils were positive for ${ }^{125}$ CXCL8 binding (Fig. 2) which was displaced in the presence of 1000-fold excess nonradiolabelled chemokine. These cells bound IL-8 in all locations within the synovium: within blood vessels; close to blood vessels in the extravascular tissue; and close to (or at) the intimal surface. Neutrophils did not show any signal for binding CCL2, CCL3 and CCL5 (Fig. 2). No major differences in neutrophil chemokine binding were apparent between the four patients who had these cells in their synovia.

\section{Immunolocalisation of CXCR1 and CXCR2}

To define the molecular identity of the ${ }^{125}$ l-CXCL8 binding sites on synovial macrophages and neutrophils, immunohistochemistry was performed to examine expression of CXCR 1 and CXCR2 by these cells. Sections from the same blocks of synovia used for radiolabelled chemokine binding were treated with antibodies to CXCR1, CXCR2 and CD68. Samples from every RA and non-RA patient showed expression of both CXCR1 and CXCR2 by macrophages in the subintima and intima (Supplementary Fig. 2 and Fig. 3). Similarly, in RA samples that possessed neutrophils, immunoreative CXCR1 and CXCR2 was displayed by these cells throughout the subintimal and intimal layers; the staining intensity for CXCR2 was more strong than for CXCR1 (Fig. 3c). Sections treated with rabbit lgG instead of CXCR1 or CXCR2 were negative for macrophage and neutrophil staining (Fig. 3d).

\section{Figure 2}
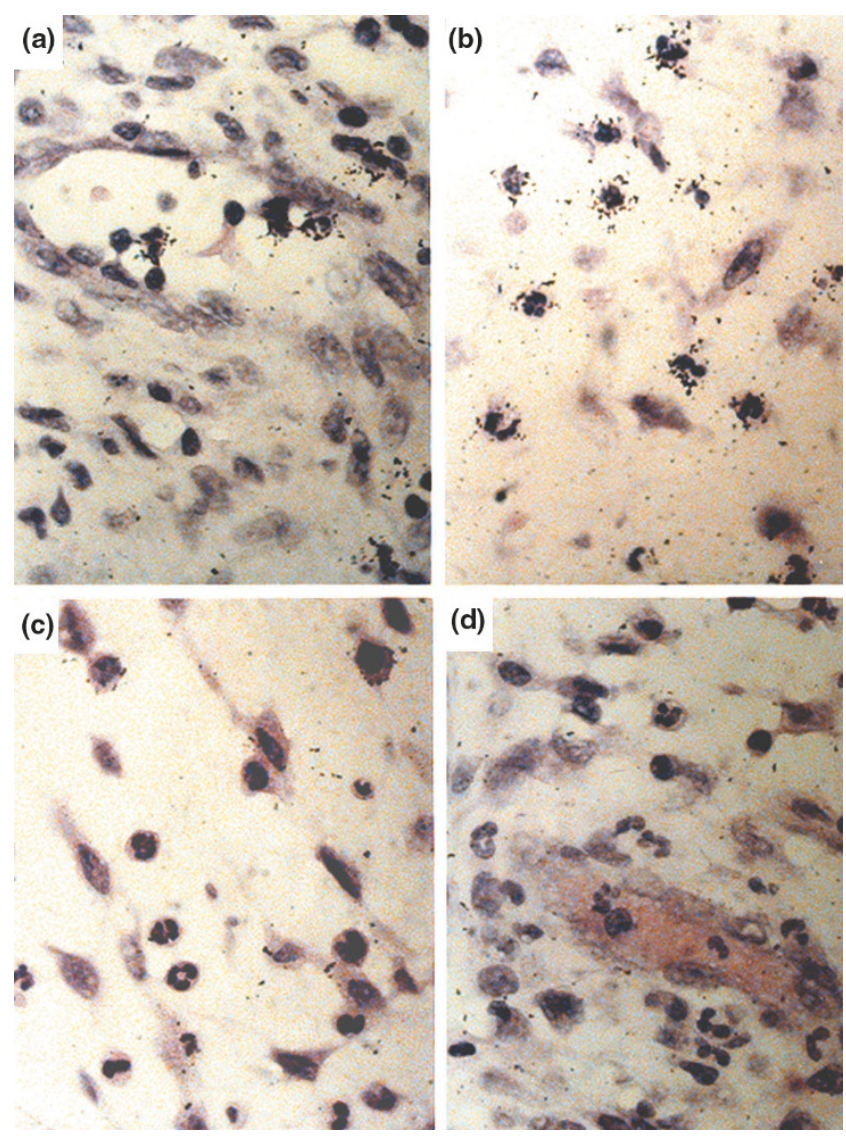

Chemokine binding to neutrophils in rheumatoid synovia. (a) CXCL8 binds to marginated neutrophils within a blood vessel. (b) CXCL8 binds to neutrophils in the subintimal tissue. There was a lack of binding of CCL5 (c) and CCL3 (d) to neutrophils in the subintima. Magnification $\times 470(\mathrm{a})-(\mathrm{d})$.

\section{Discussion}

The results of the present study show the presence of chemokine binding sites on macrophages and neutrophils 
Figure 3
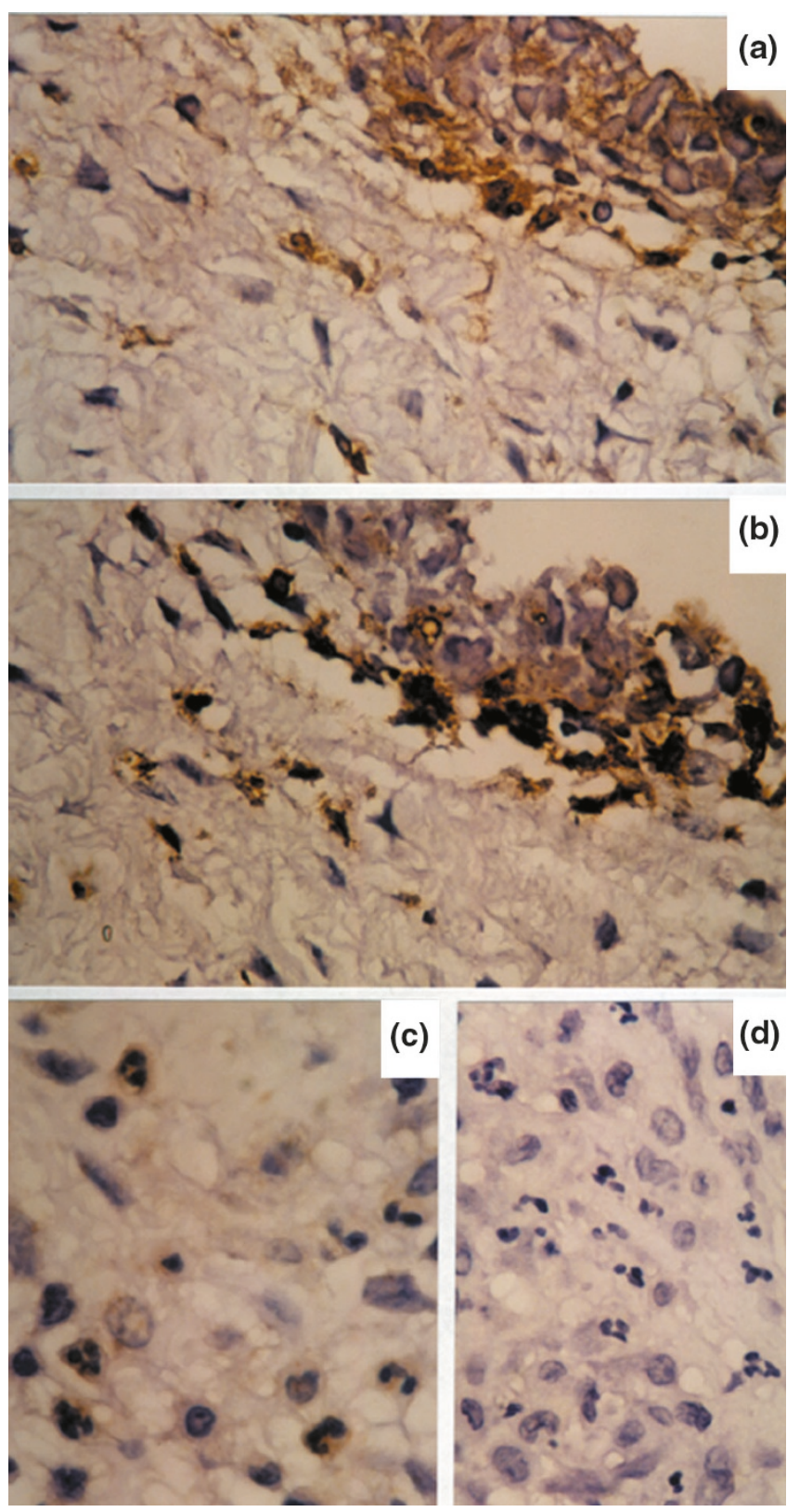

Immunohistochemistry of CXCR2 in the synovium using immunoperoxidase and diaminobenzidine (brown) staining. (a) Section of rheumatoid synovium treated with a CXCR2 antibody. CXCR2 is expressed on macrophages in the intima. (b) Adjacent section to (a) treated with an anti-CD68 antibody. (c) CXCR2 is present in neutrophils in the rheumatoid synovium. (d) There was a lack of staining when sections were incubated with rabbit lgG instead of CXCR1 or CXCR2. Magnification $\times 380(a),(b)$ and $(d)$; magnification $\times 470$ (c)

in the RA synovium. These sites were evident around blood vessels of the subintima, throughout the subintimal stroma and in the intima. In RA there is increased recruitment of monocytes, which migrate into the synovial subin- tima and to the intima, presumably following a chemotactic gradient [3]. The increase in synovial macrophage numbers is mainly due to enhanced recruitment since there appears to be little contribution from in situ proliferation of these cells [21], although deficient apoptosis may have an effect on increasing cell number [1]. There is also increased recruitment of neutrophils in RA, migrating from subintimal venules, across the synovium and into the synovial fluid where they can occur in large numbers. The binding of CCL2, CCL3, CCL5 and CXCL8 to macrophages and CXCL8 binding to neutrophils suggests that these receptors may be involved in signaling the migration of the phagocytes through the RA synovium into tissue microcompartments and fluid.

The finding that the proportion and percentage of chemokine binding sites on macrophages increases in the inflamed intima of RA and non-RA synovia suggests that these receptors may function in chronic severe synovitis in RA and more mild synovitis associated with joint damage/ degeneration in non-RA pathology. In the cases of CCL2, CCL3 and CCL5 there were no differences in the percentage of chemokine-positive cells in inflamed regions of the RA and non-RA intima. However, there were fewer CXCL8 positive cells in the inflamed RA intima than in the inflamed non-RA intima. The RA synovia were obtained from patients with long-standing disease whereas the nonRA samples were essentially from patients with joint symptoms of shorter duration (Supplementary Table 1). One explanation is that there may be temporal changes in chemokine receptor expression, which could explain this difference between RA and non-RA CXCL8 binding. In this respect, temporal changes in chemokine expression have been reported in human RA and an animal model of RA [22,23]. Alternatively the difference in CXCL8 binding could relate to variation in inflammatory mechanisms or a response to drug treatment in the RA group.

The present experimental approach was taken with the aim of finding out if receptors on phagocytes bind chemokines in situ, and showed that the receptors are available and functional in terms of binding chemokines. Our results agree with in situ studies in human skin, where macrophages also express binding sites for radiolabelled CCL3, CCL5 and CXCL8 $[24,25]$. The disadvantage with the radioligand technique is the lack of definition regarding the molecular nature of the receptors. In contrast, immunohistochemistry or flow cytometry have the advantage of molecular identification, but can not show definitively if the receptors bind ligands. Immunohistochemistry showed that both CXCR1 and CXCR2 were expressed by synovial macrophages and neutrophils, suggesting that the CXCL8 binding sites on these cells were CXCR1 and CXCR2.

A recent immunohistochemical study has shown the presence of CCR1, CCR2 and CCR5 on CD68+ 
macrophages in the RA synovium, but not CCR4 [17]. Since CCL2 is a ligand for CCR2, and both CCL3 and CCL5 are ligands for both CCR1 and CCR5 [11], these receptors are probably the CC chemokine binding sites on the macrophages in the present study. The lack of CCL2, CCL3 and CCL5 binding to synovial neutrophils suggests little or no expression of the corresponding CC chemokine receptors on these cells. This is in agreement with other studies showing lack of CCL2 binding to blood neutrophils and general lack of chemotactic response of these cells to CC chemokines [26], although recent reports indicate that neutrophils, in response to certain cytokines, are capable of expressing CC chemokine receptors $[27,28]$.

\section{Conclusion}

This study demonstrates the expression of available chemokine binding sites for CCL2, CCL3, CCL5 and CXCL8 on $\mathrm{CD}^{+} 8^{+}$macrophages in the subintimal and intimal layers of rheumatoid and nonrheumatoid synovia. Chemokine binding sites for CXCL8, but not for CCL2, CCL3 or CCL5, were found on neutrophils in the rheumatoid synovium. These receptors may mediate the recruitment of phagocytes to the subintima, intima or synovial fluid and could provide potential therapeutic targets.

\section{Acknowledgments}

We gratefully acknowledge funding from the Droitwich Medical Trust and Smith's Charity, UK. We wish to thank the following surgeons for their assistance in obtaining synovia: Mr C McGeoch, Mr D Rees, Mr L van Niekerk and Mr S White. Acknowledgement is given to P Evans, N Harness, M Pritchard and L Shaw for histological expertise. This work was undertaken by the Robert Jones and Agnes Hunt Orthopaedic and District Hospital NHS Trust, which receives a proportion of its funding from the NHS Executive. The views expressed in this publication are those of the authors.

\section{References}

1. Firestein GS: Rheumatoid synovitis and pannus. In Rheumatology. Edited by Klippel JH, Dieppe PA. London: Mosby; 1998: 13.1-13.24.

2. Edwards SW, Hallet MB: Seeing the wood from the trees: the forgotten role of neutrophils in rheumatoid arthritis. Immunol Today 1997, 18:320-324.

3. Edwards JCW: The synovium. In Rheumatology. Edited by Klippel JH, Dieppe PA. London: Mosby; 1998:6.1-6.8.

4. Edwards JCW, Willoughby DA: Demonstration of bone marrow derived cells in synovial lining by means of giant intracellular granules as genetic markers. Ann Rheum Dis 1982, 41:177-182.

5. Athanasou NA: Synovial macrophages. Ann Rheum Dis 1995, 54:392-394.

6. Hollingsworth JW, Siegel ER, Creasey WA: Granulocyte survival in synovial exudate of patients with rheumatoid arthritis and other inflammatory joint diseases. Yale J Biol Med 1967, 39: 289-296.

7. Mohr $\mathrm{W}$, Menninger $\mathrm{H}$ : Polymorphonuclear granulocytes at the pannus-cartilage junction in rheumatoid arthritis. Arthritis Rheum 1980, 23:1413-1414.

8. Szekanecz Z, Strieter RM, Kunkel SL, Koch AE: Chemokines in rheumatoid arthritis. Springer Semin Immunopathol 1998, 20: 115-132.

9. Taylor PC, Peters M, Paleolog E, Chapman PT, Elliot MJ, McCloskey R, Feldman M, Maini RN: Reduction of chemokine levels and leukocyte traffic to joints by tumor necrosis factor $\alpha$ blockade in patients with rheumatoid arthritis. Arthritis Rheum 2000, 43:38-47.
10. Hayashida K, Nanki T, Girschick H, Yavuz S, Ochi T, Lipsky P: Synovial stromal cells from the rheumatoid arthritis patients attract monocytes by producing MCP-1 and IL-8. Arthritis Res 2001, 3:118-126.

11. Horuk R: Chemokine receptors. Cytokine Growth Factor Rev 2001, 12:313-335.

12. Loetscher $P$, Uguccioni $M$, Bordoli L, Baggiolini M, Moser B, Chizzolini C, Dayer J-M: CCR5 is characteristic of Th1 lymphocytes. Nature 1998, 391:344-345.

13. Mack M, Bruhl H, Gruber R, Jaeger C, Cihak J, Eiter V, Plachy J, Stangassinger M, Uhlig K, Schattenkirchner M, Schlondorff D: Predominance of mononuclear cells expressing the chemokine receptor CCR5 in synovial effusions of patients with different forms of arthritis. Arthritis Rheum 1999, 42:981988.

14. Buckley CD, Amft N, Bradfield PE, Pilling D, Ross E, Arenzanaseisdedos F, Amara A, Curnow SJ, Lord JM, Scheel-Toellner D, Salmon M: Persistent induction of the chemokine receptor CXCR4 by TGF-1 on synovial T cells contributes to their accumulation within the rheumatoid synovium. J Immunol 2000, 165:3423-3429.

15. Nanki T, Hayashida K, El-gabalawy HS, Suson S, Shi K, Girschick HJ, Yavuz S, Lipsky PE: Stromal cell-derived factor-1-CXC chemokine receptor 4 interactions play a central role in CD4+ $\mathrm{T}$ cell accumulation in rheumatoid arthritis synovium. J Immunol 2000, 165:6590-6598.

16. Nanki T, Lipsky PE: Cytokine, activation marker, and chemokine receptor expression by individual CD4+ memory cells in rheumatoid arthritis synovium. Arthritis Res 2000, 2: 415-423.

17. Katschke KJ, Rottman JB, Ruth JH, Qin S, Wu L, LaRosa G, Ponath P, Park CC, Pope RM, Koch AE: Differential expression of chemokine receptors on peripheral blood, synovial fluid, and synovial tissue monocytes/macrophages in rheumatoid arthritis. Arthritis Rheum 2001, 44:1022-1032.

18. Kirkham B, Portek I, Lee CS, Stavros B, Lenarczyk A, Lassere M, Edmonds J: Intraarticular variability of synovial membrane histology, immunohistology, and cytokine mRNA expression in patients with rheumatoid arthritis. J Rheumatol 1999, 26:777784.

19. Hub $E$, Rot $A$ : Methods for study of chemokine receptors in the tissues. Methods 1996, 10:119-125.

20. Addison CL, Daniel TO, Burdick MD, Liu H, Ehlert JE, Xue YY, Buechi L, Walz A, Richmond A, Strieter RM: The CXC chemokine receptor 2, CXCR2, is the putative receptor for ELR+ CXC chemokine-induced angiogenic activity. J Immunol 2000, 165:5269-5277.

21. Ceponis A, Kontinnen YT, Imai S, Tamulaitiene M, Li TF, Xu JW, Hietanen J, Santavirta S, Fassbender HG: Synovial lining, endothelial and inflammatory mononuclear proliferation in synovial membranes in psoriatic and reactive arthritis: a comparative quantitative morphometric study. $\mathrm{Br} J$ Rheumatol 1998, 37:170-178.

22. Szekanecz Z, Halloran MM, Volin M, Woods JM, Strieter RM, Haines K, Kunkel S, Burdick MD, Koch AE: Temporal expression of inflammatory cytokines and chemokines in rat adjuvantinduced arthritis. Arthritis Rheum 2000, 43:1266-1277.

23. Katrib A, Tak PP, Bertouch JV, Cuello C, McNeil HP, Smeets TJM, Kraan MC, Youssef PP: Disease duration and the expression of chemokines and matrix metalloproteinases in rheumatoid arthritis. Arthritis Rheum 2000, 43(suppl):S84.

24. Rot $A$ : Binding of neutrophil attractant/activation protein-1 (interleukin-8) to resident dermal cells. Cytokine 1992, 4:347352.

25. Hub E, Rot A: Binding of RANTES, MCP-1, MCP-3 and MIP-1 $\alpha$ to cells in human skin. Am J Pathol 1998, 152:749-757.

26. Baggiolini M, Dewald B, Moser B: Interleukin-8 and related chemotactic cytokines - CXC and CC chemokines. $A d v$ Immunol 1994, 55:97-179.

27. Bonecchi R, Polentarutti N, Luini W, Borsatti A, Bernasconi S, Locati M, Power C, Proudfoot A, Wells TNC, Mackay C, Mantovani A, Sozzano S: Up-regulation of CCR1 and CCR3 and induction of chemotaxis to CC chemokines by IFN- $\gamma$ in human neutrophils. J Immunol 1999, 162:474-479.

28. Cheng SS, Lai JJ, Lukacs NW, Kunkel SL: Granulocytemacrophage colony stimulating factor up-regulates CCR1 in human neutrophils. J Immunol 2001, 166:1178-1184. 


\section{Supplementary material}

\section{Supplementary Materials and methods In situ binding autoradiography}

Synovia were cut into approximately $2 \mathrm{~mm}^{3}$ pieces. Four samples were placed in tubes containing 0.1 to $4.0 \mathrm{ng}$ of recombinant human ${ }^{125}$-labeled ( $r$ h $\left.{ }^{125} \mathrm{l}\right)$-CXCL8 $\left(\mathrm{M}_{\mathrm{r}}=\right.$ 8400), rh 125/-CCL5 $\left(\mathrm{M}_{\mathrm{r}}=8000\right)$, rh 125l-CCL2 $\left(\mathrm{M}_{\mathrm{r}}=\right.$ $8800)$ or rh ${ }^{125} \mathrm{I}-\mathrm{CCL} 3\left(\mathrm{M}_{\mathrm{r}}=8000\right)(262 \mu \mathrm{Ci} / \mu \mathrm{g}$; NEN, Boston, USA) in $400 \mu \mathrm{l} \mathrm{Hank's} \mathrm{balanced} \mathrm{salt} \mathrm{solution} \mathrm{con-}$ taining $0.1 \%$ bovine serum albumin and $20 \mathrm{mM}$ HEPES. The samples were then incubated for one hour at room temperature on a platform shaker [19]. In these experiments, synovial samples from each patient were treated with each of the four chemokines. Initial experiments showed that binding sites were saturable over this concentration-RAnge and the optimum binding/background ratio was obtained using $0.8 \mathrm{ng}$ of chemokine; this amount was used in all the subsequent experiments. Control tubes contained 1000-fold excess of the corresponding unlabeled recombinant human chemokine (molecular mass as for radiolabelled chemokines) (PeproTech EC, London, UK; CXCL8 was kindly donated from Novartis Research Institute, Vienna, Austria). The tissue was washed four times for $10 \mathrm{~min}$ in $2 \mathrm{ml}$ Hank's balanced salt solution on a platform shaker, then fixed overnight in $4 \%$ paraformaldehyde. It was then dehydrated in alcohol, embedded in fibrowax and sectioned at $5 \mu \mathrm{m}$ thickness. Sections were deparafinized, rehydrated, air-dried and coated with Amersham LM1 emulsion (Amersham Pharmacia Biotech, Little Chalfont, UK). The slides were exposed at $4^{\circ} \mathrm{C}$ for two weeks, developed and stained in haematoxylin and eosin.

\section{Immunohistochemistry for CXCR1 and CXCR2}

Sections were deparafinized, rehydrated and in the case of CXCR1 pre-treated with $1 \%$ pronase for 10 min to unmask epitopes. Following blocking of endogenous peroxidase with $0.3 \%$ hydrogen peroxide in methanol for $30 \mathrm{~min}$, slides were rinsed in PBS and treated with a 1/60 dilution of normal goat serum for $30 \mathrm{~min}$. Sections were rinsed in PBS, incubated with CXCR1 or CXCR2 antibodies (at $1 / 50$ and $1 / 500$ dilution respectively) or rabbit lgG (at the same concentration as primary antibodies) for $30 \mathrm{~min}$. After washing with PBS, the antibodies were detected using reagents in the Vectastain ABC Elite Kit (Vector Labs, Burlingame, USA); the sections were treated with biotinylated goat anti-rabbit $\lg$ (at 1/200 dilution) for $30 \mathrm{~min}$, rinsed with PBS, incubated with streptavidin-conjugated peroxidase for $30 \mathrm{~min}$, washed with PBS, then treated with the chromogen 3,3'-diaminobenzidine for $5 \mathrm{~min}$. Sections were washed twice in PBS then water, dried and counterstained in Mayer's haematoxylin. All steps in the method were carried out at room temperature.

\section{Quantitation of synovial sections}

Sections were used from in situ binding autoradiography experiments and were quantitated blind by one observer. The sample length was $280 \mu \mathrm{m}$ of synovial intima, the width of a field of view using a $\times 63$ objective lens on a Nikon diaplan light microscope. Intimal cells were scored as being positive for chemokine binding when the autoradiographic signal was greater than that of the adjacent background. The number of positive and negative cells were counted visually in three sample lengths per section (i.e. $840 \mu \mathrm{m}$ ). The number of sections per patient was

Supplementary Table 1

Details of RA and non-RA patients

\begin{tabular}{lllcc}
\hline Gender & Age & Diagnosis/pathology & Disease duration (years) & Medication \\
\hline 1. Female & 71 & RA & 7 & An \\
2. Male & 61 & RA & 20 & St \\
3. Female & 67 & RA & 7 & St, NSAID \\
4. Male & 73 & RA & 15 & Pen, NSAID, An \\
5. Female & 52 & RA & 20 & Hyd, St, MTX, Gold, NSAID \\
6. Female & 56 & RA & 25 & - \\
7. Female & 47 & articular cartilage damage & 5 & - \\
8. Male & 43 & acl damage & $<1$ & - \\
9. Male & 46 & meniscal tear, articular cartilage damage & 7 & NSAID \\
10. Female & 46 & meniscal tear, articular cartilage degeneration & $<1$ & - \\
11. Female & 63 & meniscal tear, articular cartilage degeneration & $<1$ & - \\
12. Male & 43 & acl and articular cartilage damage & $>5$ &
\end{tabular}

acl, anterior cruciate ligament; An, analgesic; Hyd, Hydroxychloroquine; MTX, methotrexate; NSAID, non-steroidal anti-inflammatory drug; Pen, penicillamine; RA, rheumatoid arthritis; St, steroid. 


\section{Supplementary Figure 1}
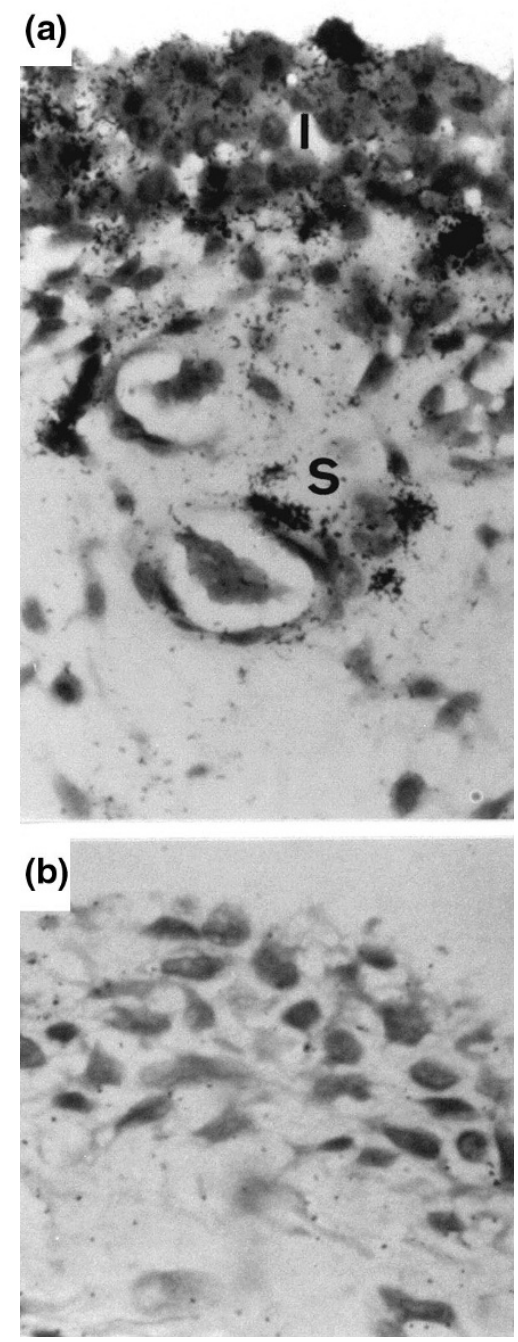

In situ receptor autoradiography showing chemokine binding to the inflamed nonrheumatoid synovium. (a) Samples of tissue were incubated with ${ }^{125}$-CCL5 and subjected to autoradiography. The chemokine binds to cells in the intima (I) and the subintima (S). (b) Samples incubated with radiolabelled chemokine in the presence of 1000 -fold excess homologous unlabelled chemokine show an absence of chemokine binding. Magnification $\times 470$ (a) and (b).

four, giving a total of $3360 \mu \mathrm{m}$ of intima measured per patient. The intima was noted as being normal where it was one to two cells thick, and inflamed where greater than two cells thick. All cells were counted except neutrophils, which only comprised $<1 \%$ of all cells sampled.

From these data, the number and percentage of positive cells in the intimal samples were obtained and expressed per $500 \mu \mathrm{m}$ of intima. Statistical analyses were by Student's $t$-test, The result was significant when $P<0.05$.

\section{Supplementary Figure 2}
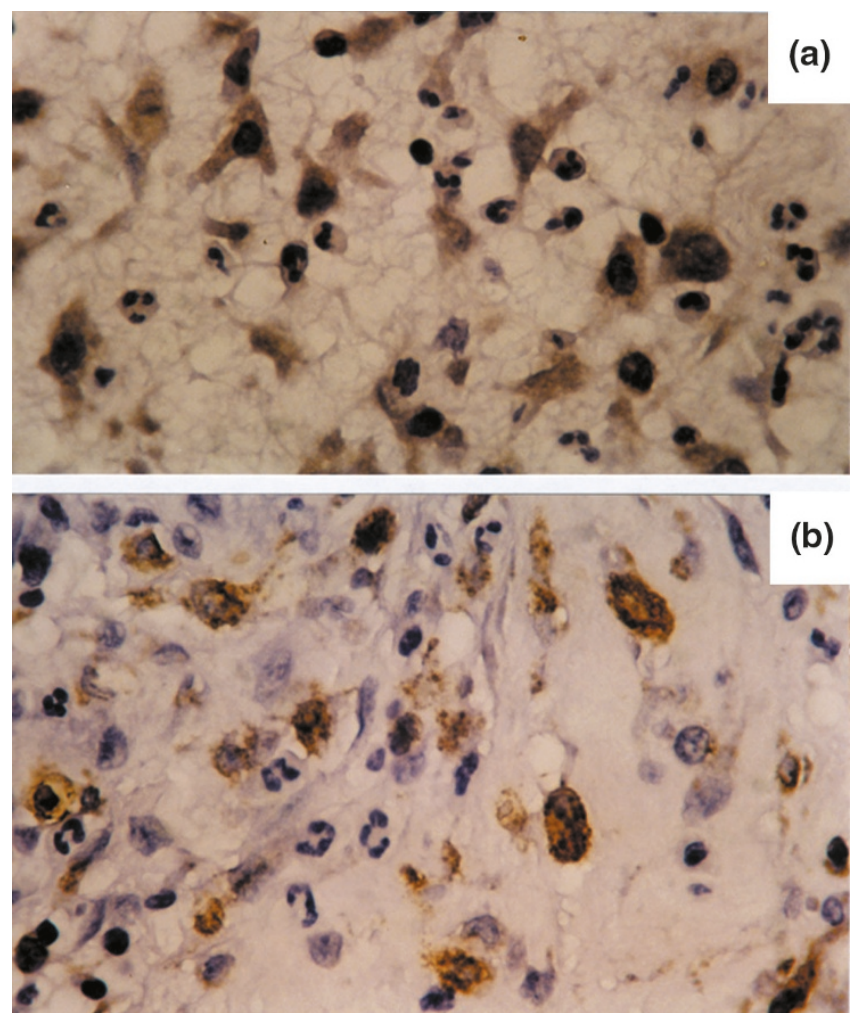

CXCR1 immunohistochemistry of the synovium using

immunoperoxidase and diaminobenzidine (brown) staining. (a) Section of a macrophage-rich infiltrate in a rheumatoid synovium treated with a CXCR1 antibody. (b) Adjacent section to (a) treated with an antiCD68 antibody as a macrophage marker. Note the presence of CXCR1 on macrophages. Magnification $\times 380$ (a) and (b).

\section{Supplementary Discussion}

The functional role of chemokine receptors in inflammatory cell recruitment is suggested from animal models of RA. Using the CC chemokine receptor antagonist MCP-1(976), a truncated analogue peptide corresponding to MCP, markedly reduces joint histopathology and symptoms in the MRL-Ipr mouse model [S1]. The CC receptor antagonist MetRANTES decreased the incidence and severity of arthritis in mouse collagen-induced arthritis [S2]. With both antagonists, mononuclear infiltration is reduced.

CCL2, CCL3, CCL5 and CXCL8 occur in human RA synovial fluid and tissue [8]. Therefore the ligands for the binding sites described here occur endogenously within the RA joint, adding further evidence towards a role for these receptors in vivo. In the RA joint the synovial macrophage is among the principle cell types that produce CCL2, CCL3 and CXCL8 $[8,17]$. The finding of chemokine receptors on these cells suggests that macrophages may amplify inflammation by attracting cells of the same type, and other cell types, into the joint 


\section{Supplementary Table 2}

Percentage of intimal cells binding chemokines per $500 \mu \mathrm{m}$ of intima

\begin{tabular}{|c|c|c|c|c|}
\hline \multirow[b]{2}{*}{ Cytokine } & \multicolumn{2}{|c|}{ Rheumatoid $(n=6)$} & \multicolumn{2}{|c|}{ Nonrheumatoid $(n=6)$} \\
\hline & Inflamed & Noninflamed & Inflamed & Noninflamed \\
\hline CXCL8 & $42 \pm 5^{*+}$ & $13 \pm 4$ & $58 \pm 5$ * & $17 \pm 2$ \\
\hline CCL2 & $56 \pm 5$ * & $27 \pm 3$ & $48 \pm 7$ * & $19 \pm 3$ \\
\hline CCL5 & $79 \pm 3$ * & $49 \pm 11$ & $66 \pm 7^{*}$ & $33 \pm 7$ \\
\hline CCL3 & $88 \pm 2$ & - & $87 \pm 5$ * & $44 \pm 6$ \\
\hline
\end{tabular}

The number of positive cells per standard length of intimal surface was counted ( $3360 \mu \mathrm{m}$ total length per patient); data are expressed separately for inflamed ( $>2$ cells thick) and noninflamed tissue ( $1-2$ cells thick). Data are expressed as mean \pm SE. $n$, number of patients. ${ }^{*}$ Significant difference between inflamed and noninflamed; ${ }^{\dagger}$ significant difference between rheumatoid and nonrheumatoid.

thereby setting up a positive feedback loop. Similar mechanisms may also be occurring with neutrophils, since in the RA joint these cells produce CXCL8 [S3] and express CXCL8 binding sites.

\section{Supplementary References}

S1. Gong J-H, Ratkay LG, Waterfield JD, Clark-Lewis I: An antagonist of monocyte chemoattractant protein $1(\mathrm{MCP}-1)$ inhibits arthritis in the MRL-Ipr mouse model. J Exp Med 1997, 186:131137.

S2. Plater-Zyberk C, Hoogewerf AJ, Proudfoot AEI, Power CA, Wells TNC: Effect of a CC chemokine receptor antagonist on collagen induced arthritis in DBA/1 mice. Immunol Lett 1997, 57:117-120.

S3. Beaulieu A, McColl S: Differential expression of two major cytokines produced by neutrophils, interleukin-8 and the interleukin-1 receptor antagonist, in neutrophils isolated from synovial fluid and peripheral blood of patients with rheumatoid arthritis. Arthritis Rheum 1994, 37:855-859. 